\title{
Development and evaluation of organic/inorganic combined gel for conformance control in high temperature and high salinity reservoirs
}

\author{
Hong He $\cdot$ Yefei Wang $\cdot$ Xiaojie Sun • \\ Peng Zhang $\cdot$ Dandan Li
}

Received: 5 November 2013/Accepted: 10 June 2014 / Published online: 1 July 2014

(C) The Author(s) 2014. This article is published with open access at Springerlink.com

\begin{abstract}
Polymer gels have been successfully applied to control undesired water production for many years, however, due to poor long-term thermal stability and salt tolerance, conventional polymer gels present some limitations for application in high temperature and high salinity reservoirs. In this paper, an organic/inorganic combined gel composed of polymer with low degree of hydrolysis, phenol formaldehyde resin and inorganic silicate was proposed and developed. The effects of concentration, temperature on gelation time were studied. Long-term thermal stability, salt tolerance and permeability reduction ability were investigated. Results showed that based on proper gelation time and economical cost, the formulation of the organic/inorganic combined gel was optimized. The gelation time decreased from 54.0 to $15.5 \mathrm{~h}$ with increasing temperature from 100 to $130{ }^{\circ} \mathrm{C}$. After aging for 60 days in simulated formation brine with high total dissolved solids (TDS: $20 \% \mathrm{NaCl}+2.5 \% \mathrm{CaCl}_{2}$ ) at $130{ }^{\circ} \mathrm{C}$, compared with polymer gel, the organic/inorganic combined gel had better long-term thermal stability and salt tolerance. Sandpack flow experimental results showed that for the organic/inorganic combined gel composed of $0.3 \mathrm{wt} \%$ polymer, $4.0 \mathrm{wt} \%$ resin and $3.0 \mathrm{wt} \%$ inorganic silicate, after aging for 60 days at $130{ }^{\circ} \mathrm{C}$, the combined gel showed approximately $85 \%$ permeability reduction. Therefore,
\end{abstract}

H. He $(\bowtie) \cdot$ Y. Wang $\cdot$ X. Sun · D. Li

College of Petroleum Engineering, China University

of Petroleum (East China), No.66, West Changjiang Road, Qingdao 266580, China

e-mail: hehong1103@163.com

P. Zhang

College of Chemistry and Chemical Engineering,

Chongqing University of Science and Technology,

Chongqing 401331, China these results indicate that the combined gel studied here can be a good candidate for controlling water production in high temperature and high salinity reservoirs.

Keywords Combined gel · Conformance control · High temperature $\cdot$ High salinity

\section{Introduction}

Water flooding is one of the most common methods used to improve oil recovery. However, as more and more oilfields become mature, the breakthrough of water along the high permeability channels often occurs, resulting in poor sweep efficiency and excessive water production. Excessive water production has caused major problems due to decreased oil production and increased costs of lifting, separating and disposing large amounts of produced water, which has attracted more concerns on water control technology. Conformance control that generally refers to using chemical or mechanical methods to reduce undesired water production has been proved as an effective water control technology, which can improve sweep efficiency and thus result in an increase in ultimate oil recovery (Liu et al. 2010). Chemical-based conformance control has been successfully used to improve oil recovery of mature water flooding reservoirs. However, for high temperature and high salinity reservoirs, not many options are available. Polymer gels have been successfully applied to control water production from the hydrocarbon wells (Sydansk and Southwell 2000). However, Due to thermal hydrolysis under high temperature, some of the amide groups $\left(-\mathrm{CONH}_{2}\right)$ on polymer backbone convert to carboxylate groups that crosslink with divalent cations, resulting in syneresis or precipitation of polymer gel (Kabir 2001). 
Therefore, due to poor long-term thermal stability and salt tolerance, the conventional polymer gels present some limitations for the application in high temperature and salinity reservoirs. To extend the polymer gel application scope, some thermally stable polymer gels that composed of copolymers and organic crosslinkers have been reported in previous literatures (Moradi-Araghi et al. 1993; Albonico et al. 1995; Bryant et al. 1997; Hardy et al. 1998; Mary et al. 1999; Moradi-Araghi 2000; Vasquez et al. 2005; Eoff et al. 2007; Banerjee et al. 2008; Al-Muntasheri et al. 2009; Sengupta et al. 2012; Yadav and Mahto 2013). The copolymers reported in previous literatures are copolymer of acrylamide and $t$-butylacrylate (PAtBA), and copolymer of acrylamide and acrylamido-2-methylpropane sulfonic acid (AMPS) and the organic crosslinkers are phenol formaldehyde resin and polyethyleneimine (PEI). However, we found little research focused on the gel thermal stability and salt tolerance in the high salinity formation brines, which are crucial to the effectiveness of gel treatments. Sodium silicate based gel has been used to control water production (Nasr-El-Din and Taylor 2005), however, the main problems associated with the sodium silicate based gel are short gelation time and low gel strength in high temperature and high salinity reservoirs. Moreover, the challenge for sodium silicate based gel is the compatibility with the formation brine in the presence of calcium ions or magnesium ions. A white precipitation of calcium silicate or magnesium silicate forms immediately upon mixing with the formation brine.

The single polymer gel or sodium silicate based gel has some disadvantages, to improve the gel compatibility, thermal stability and salt tolerance, organic/inorganic combined gel composed of polymer, organic crosslinker and inorganic material was proposed, which can have synergetic effect and achieve better gel treatment efficiency. Therefore, in this paper, an organic/inorganic combined gel composed of polymer with low degree of hydrolysis, phenol formaldehyde resin and inorganic silicate was developed. The possible gelation mechanism is as follows: (1) Gelation reaction between the amide group $\left(-\mathrm{CONH}_{2}\right)$ of polymer and hydroxymethyl $\left(-\mathrm{CH}_{2} \mathrm{OH}\right)$ group of phenol formaldehyde resin can occur to form three-dimensional network structure.

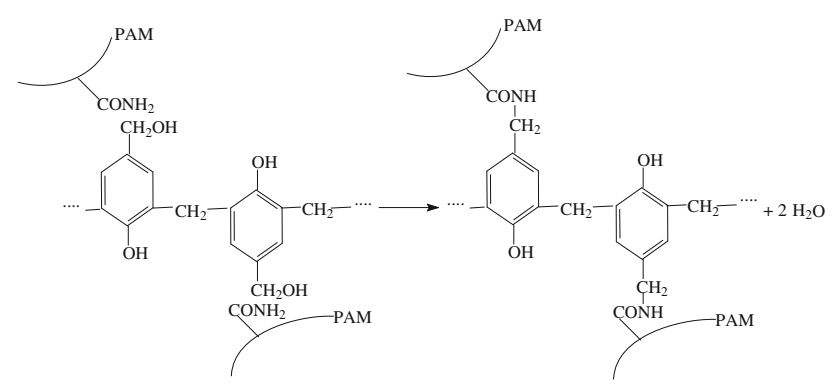

(2) The water-soluble inorganic silicate is converted into silicic acid at high temperature.<smiles>C[13CH2]O[Si](=O)O[Si](=O)O[Si](=O)O[Si](=O)O[Si](=O)O[Si](=O)O</smiles>

(3) The polycondensation of silicic acid occurs and another three-dimensional network structure is formed.

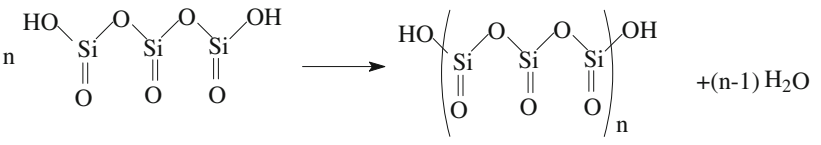

Based on the previous literatures, we found that little research had been done on the use of organic/inorganic combined gel to control water production in high temperature and salinity reservoirs. To ensure that the combined gel can be applied to control water production in high temperature and salinity reservoirs, the objectives of this work are to: (1) optimize the formulation of combined gel based on proper gelation time and economical cost; (2) evaluate the long-term thermal stability and salt tolerance; (3) evaluate permeability reduction to brine as a function of aging time, which can account for the feasible application of water control using the combined gel in high temperature and salinity reservoirs.

\section{Experimental studies}

\section{Materials}

The polyacrylamide (PAM) used in this study was supplied in powder form. The molecular weight and degree of hydrolysis was $9.6 \times 10^{6} \mathrm{~g} / \mathrm{mol}$ and $3.62 \%$ respectively. The inorganic silicate solution was a viscous fluid with an active content of $35 \mathrm{wt} \%$. Deionized water and the fresh water were obtained in own laboratory. The simulated formation brine contained $20 \% \mathrm{NaCl}$ and $2.5 \% \mathrm{CaCl}_{2}$. The gelant solutions with various formulations were prepared with fresh water containing $250 \mathrm{mg} \mathrm{L}^{-1} \mathrm{NaCl}$.

Preparation of gelant solution

First, deoxygenated fresh water was used to prepare the polymer solution. Then the predetermined amounts of resin and silicate were added to the polymer solution. The gelant solution was thoroughly mixed by using a magnetic stirrer. Then the gelant solution was injected into an ampoule tube placed inside an oven set at the desired temperature. The 
ampoule tube was periodically removed from the oven for observation.

Gelation time and gel strength measurement

The gelation time was measured by Sydansk (1988) gelstrength code method. Sydansk gel-strength code method is a semi-quantitative measurement of the gelation time and the gel strength. In this study, the gelation time is defined as the time when the gel strength of gelant solutions reaches grade $\mathrm{G}$ (Grade $\mathrm{G}$ : the gel is described as moderately deformable nonflowing gel and flows approximately half way down the bottle upon inversion).

Long-term thermal stability and salt tolerance

The long-term thermal stability and salt tolerance were evaluated by measuring the degree of syneresis as a function of aging time. The experimental procedure was as follows: (1) measure the initial mass of formed combined gel $m_{\mathrm{o}}$; (2) place the formed combined gel inside a steel container containing simulated formation brine with high total dissolved solids (TDS: $20 \% \mathrm{NaCl}+2.5 \% \mathrm{CaCl}_{2}$ ). The steel container was placed inside an oven at $130{ }^{\circ} \mathrm{C}$ and the steel container was periodically removed from the oven. Measure the mass of formed combined gel at different aging time $m_{(\mathrm{t})}$; (3) calculate the degree of syneresis (DS) at different aging time according to the following equation:

$\mathrm{DS}=\frac{m_{0}-m_{(t)}}{m_{0}} \times 100 \%$.

Sandpack flow experiments

Sandpack flow experiments were conducted on the sandpacks with the diameter of $2.5 \mathrm{~cm}$ and a length of $20 \mathrm{~cm}$ to evaluate the permeability reduction of the combined gel as a function of aging time at $130{ }^{\circ} \mathrm{C}$. The experimental procedure was as follows: (1) The sandpacks were filled with clean quartz sands and saturated with simulated formation brine; (2) the sandpacks were flooded with simulated formation brine until the pressure drop across the sandpacks was stable. Permeability to brine $k_{w 0}$ was measured at a flow rate of $1 \mathrm{~mL} \mathrm{~min}{ }^{-1}$. (3) Then $0.3 \mathrm{PV}$ (pore volume) gelant solution was injected into sandpacks at a flow rate of $1 \mathrm{~mL} \mathrm{~min}{ }^{-1}$. After injection, the sandpacks were shut in for $48 \mathrm{~h}$ to ensure that the gelant solution can form gel; (4) then the simulated formation brine was injected into the sandpacks to measure the permeability $k_{w 1}$ after the gel treatment; (5) calculate the percent permeability reduction (PPR) to evaluate the effectiveness of the gel in reducing permeability according to the following equation:
$\mathrm{PPR}=\left(k_{w 0}-k_{w 1}\right) / k_{w 0} \times 100 \%$.

\section{Results and discussion}

Formulation of combined gel optimization

The formulation of combined gel that composed of polymer, phenol formaldehyde resin, and inorganic silicate was optimized by studying the effects of component concentrations on the gelation time and the gel strength. In this study, the gel strength of the combined gel with various formulations can mainly reach grade I (Grade I: the gel is described as rigid gel and there is no gel-surface deformation upon inversion). The appearance of the formed combined gel is shown in Fig. 1.

\section{Effect of polymer concentration}

The polymer concentration is critical to the formation of three-dimensional network structure, which can greatly affect the gelation time. The effect of polymer concentration on gelation time was studied by preparing different gelant solutions containing $4.0 \mathrm{wt} \%$ resin, $3.0 \mathrm{wt} \%$ inorganic silicate and polymer concentrations varied from 0.1 to $0.4 \mathrm{wt} \%$ at $130{ }^{\circ} \mathrm{C}$. Figure 2 shows the gelation results of gelant solutions containing various polymer concentrations. The gelation time decreased from 32.0 to $12.0 \mathrm{~h}$ with increasing the polymer concentration. As the polymer concentration increased, the cross-linking reaction chances between the amide group $\left(-\mathrm{CONH}_{2}\right)$ and hydroxymethyl group $\left(-\mathrm{CH}_{2} \mathrm{OH}\right)$ increased, resulting in a decrease in gelation time. Therefore, according to proper gelation time and economical cost, the reasonable polymer concentration should range from 0.2 to $0.3 \mathrm{wt} \%$.

\section{Effect of resin concentration}

The effect of resin concentration on gelation time was studied by preparing different gelant solutions containing $0.3 \mathrm{wt} \%$ polymer, $3.0 \mathrm{wt} \%$ inorganic silicate and the resin concentrations varied from 1.5 to $5.0 \mathrm{wt} \%$ at $130{ }^{\circ} \mathrm{C}$. Figure 3 shows the gelation results of gelant solutions containing various resin concentrations. The gelation time decreased from 30.0 to $7.0 \mathrm{~h}$ with increasing resin concentration. As the resin concentration increased, the crosslinking reaction chances between the amide group ($\left.\mathrm{CONH}_{2}\right)$ and hydroxymethyl group $\left(-\mathrm{CH}_{2} \mathrm{OH}\right)$ increased, resulting in a decrease in gelation time. Therefore, according to proper gelation time and economical cost, the reasonable resin concentration should range from 2.5 to 4.0 $\mathrm{wt} \%$. 
Fig. 1 The appearance of formed combined gel
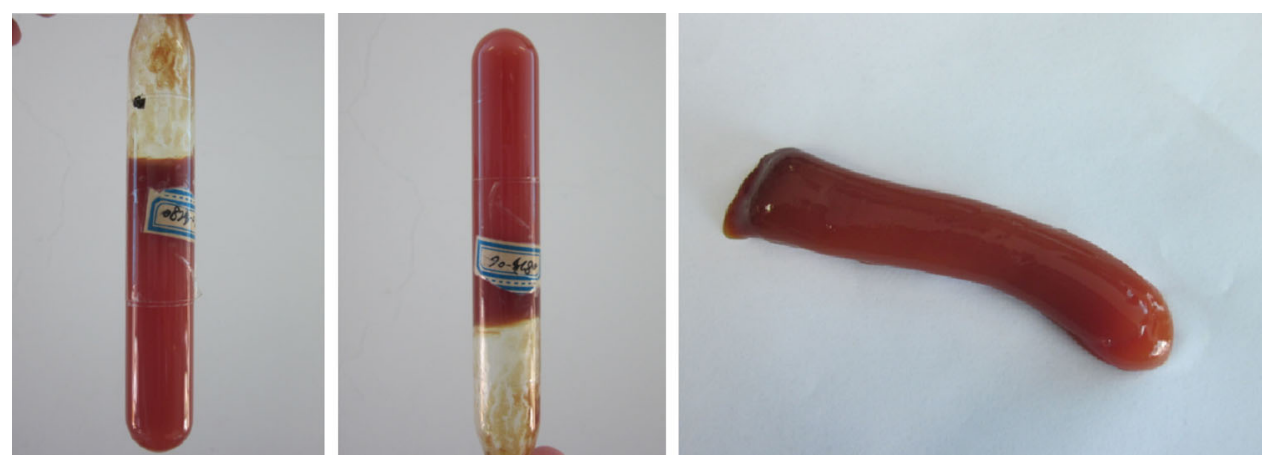

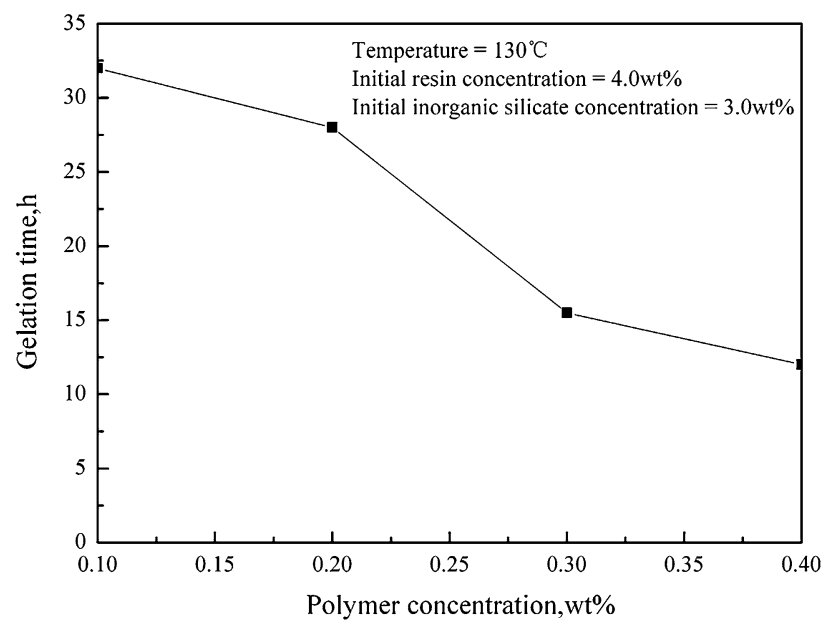

Fig. 2 Effect of polymer concentration on gelation time $\left(130^{\circ} \mathrm{C}\right)$

\section{Effect of inorganic silicate}

The inorganic silicate can improve the gelation performance greatly by forming another three-dimensional network structure. The effect of inorganic silicate concentration on gelation time was studied by preparing different gelant solutions containing $0.3 \mathrm{wt} \%$ polymer, $4.0 \mathrm{wt} \%$ resin, and the inorganic silicate concentrations varied from 1.0 to $8.0 \mathrm{wt} \%$ at $130{ }^{\circ} \mathrm{C}$. Figure 4 shows the gelation results of gelant solutions containing various inorganic silicate concentrations. As the inorganic silicate concentration increased from 1.0 to 8.0 wt $\%$, the gelation time decreased from 19 to $4 \mathrm{~h}$. As the inorganic silicate concentration increased, the reaction rate of inorganic silicate forming three-dimensional network structure at high temperature was accelerated, resulting in a decrease in gelation time. Therefore, according to proper gelation time and economical cost, the reasonable inorganic silicate concentration should range from 3.0 to $5.0 \mathrm{wt} \%$.

\section{Effect of temperature}

The gelation time is dependent on the component concentrations and the temperature. For the gelant solution

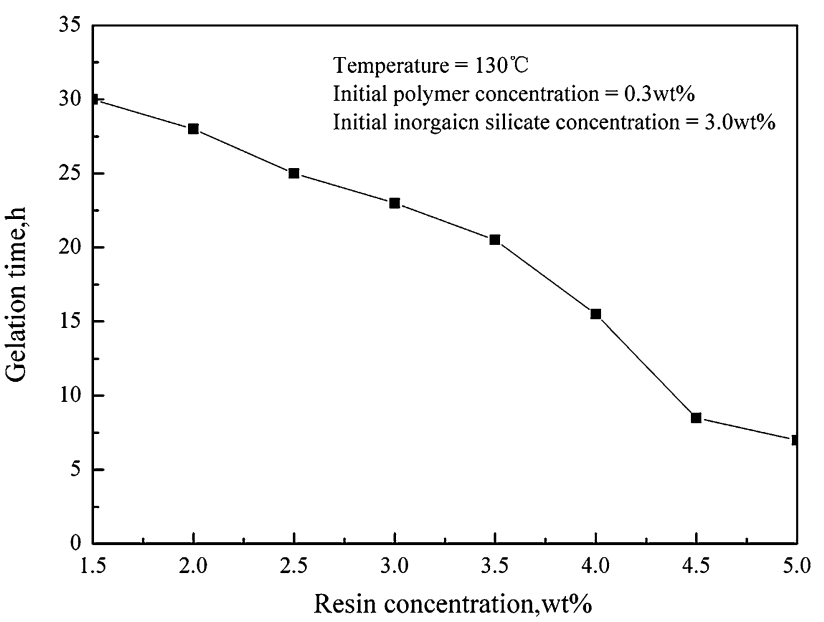

Fig. 3 Effect of resin concentration on gelation time $\left(130^{\circ} \mathrm{C}\right)$

containing $0.3 \mathrm{wt} \%$ polymer, $4.0 \mathrm{wt} \%$ resin and $3.0 \mathrm{wt} \%$ inorganic silicate, the effect of temperature on gelation time was studied. Figure 5 shows the gelation time of gelant solution containing $0.3 \mathrm{wt} \%$ polymer, $4.0 \mathrm{wt} \%$ resin and 3.0 $\mathrm{wt} \%$ inorganic silicate at various temperatures. The gelation time decreased from 54.0 to $15.5 \mathrm{~h}$ with increasing temperature from 100 to $130{ }^{\circ} \mathrm{C}$. As the temperature increased, the cross-linking reaction rate increased and resulted in a decrease in gelation time. The gelation time was correlated to the temperature according to the Arrhenius' equation:

$k=k_{0} e^{-E_{a} / R T}$

where $k$ is reaction rate constant, $k_{0}$ is the frequency factor, $E_{\mathrm{a}}$ is the activation energy $(\mathrm{kJ} / \mathrm{mol}), R$ is the gas constant $(\mathrm{kJ} / \mathrm{mol} \mathrm{K})$ and $T$ is absolute temperature (K) (Fig. 6). The Eq. (3) was modified by introducing the gelation time $\left(t_{\mathrm{g}}\right)$ instead of the reaction rate constant $k$. The modified equation was as follows (Nasr-El-Din and Taylor 2005):

$t_{g}=M e^{E_{a} / R T}$

where $t_{\mathrm{g}}$ is the gelation time (h), $M$ is the time constant (h), $E_{\mathrm{a}}$ is the activation energy $(\mathrm{kJ} / \mathrm{mol}), R$ is the universal gas 


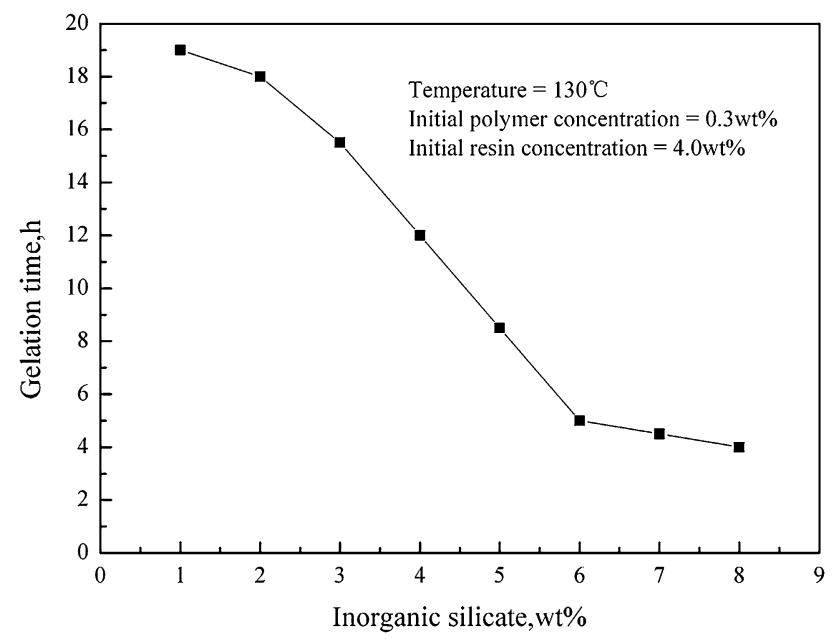

Fig. 4 Effect of inorganic silicate on gelation time $\left(130{ }^{\circ} \mathrm{C}\right)$

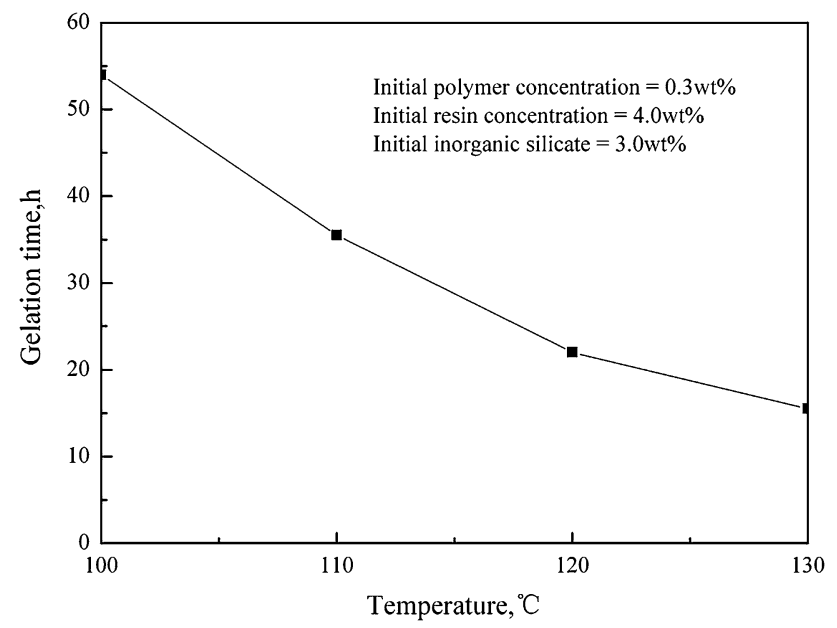

Fig. 5 Effect of temperature on gelation time

constant $(\mathrm{kJ} / \mathrm{mol} \mathrm{K})$ and $T$ is absolute temperature $(\mathrm{K})$. Then the Eq. (4) was transformed into the following equation:

$\ln \left(t_{g}\right)=\frac{E_{a}}{R T}+\ln M$.

As we can see from the Eq. (5), there is a linear relationship between the $\ln \left(t_{\mathrm{g}}\right)$ and the inverse of the absolute temperature $(1 / \mathrm{T})$. Figure 5 shows the plot of $\ln$ $\left(t_{\mathrm{g}}\right)$ versus the inverse of absolute temperature. Calculated from the slope of Fig. 5, the activation energy $E_{\mathrm{a}}$ of the gelant system was $52.8 \mathrm{~kJ} / \mathrm{mol}$. Moreover, it is worth noting that the effect of temperature on the gelation time can be predicted by using Eq. (4).

Long-term thermal stability and salt tolerance

The long-term thermal stability and salt tolerance are crucial to the effectiveness of gel treatments in high

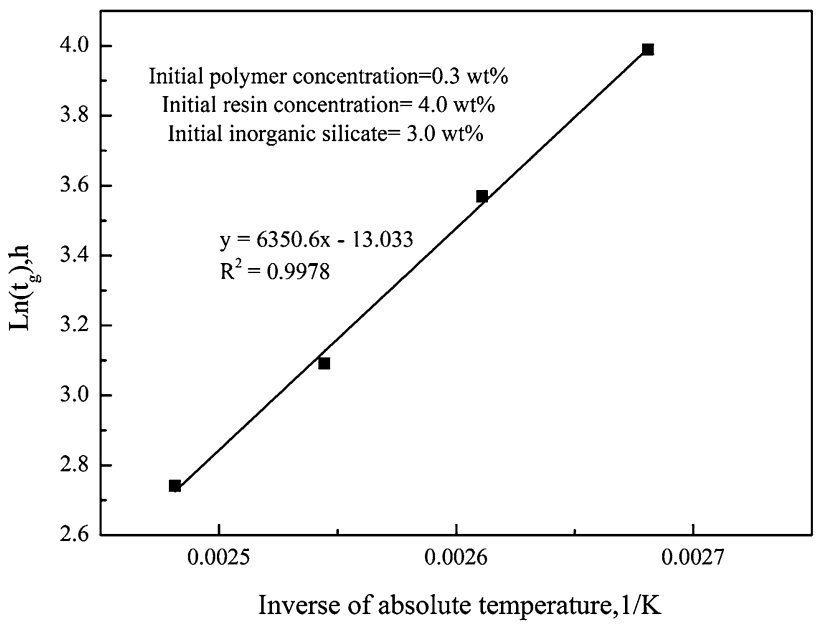

Fig. 6 Arrhenius-type plot of gelation time and temperature

temperature and high salinity reservoirs. In this study, the long-term thermal stability and salt tolerance were evaluated by measuring the degree of syneresis as a function of aging time. Figure 7 shows the degree of syneresis observed in bulk gel samples as a function of aging time. After aging for 60 days in simulated formation brine with high total dissolved solids (TDS: $20 \% \mathrm{NaCl}+2.5 \%$ $\mathrm{CaCl}_{2}$ ) at $130{ }^{\circ} \mathrm{C}$, for polymer gel composed of $0.3 \mathrm{wt} \%$ polymer and $4.0 \mathrm{wt} \%$ resin, about $92 \%$ syneresis was observed, while for the organic/inorganic combined gel that composed of $0.3 \mathrm{wt} \%$ polymer, $4.0 \mathrm{wt} \%$ resin and 3.0 wt $\%$ inorganic silicate, about $40 \%$ syneresis was observed. The reasons for the phenomenon could be as follows (Liang and $\mathrm{Li}$ 2001): Gelation reaction between the amide group $\left(-\mathrm{CONH}_{2}\right)$ of polymer and hydroxymethyl ($\mathrm{CH}_{2} \mathrm{OH}$ ) group of phenol formaldehyde resin could occur to form three-dimensional network structure. Moreover, the inorganic silicate could form another three-dimensional network structure at high temperature. Then compared with single polymer gel network structure, the combined network structure had less free water content and high strength structure, which can improve the gel thermal stability properties.

Therefore, compared with polymer gel, the organic/ inorganic combined gel had better long-term thermal stability and salt tolerance.

\section{Sandpack flow experiment}

Sandpack flow experiments were conducted to evaluate the permeability reduction of the combined gel as a function of aging time at $130{ }^{\circ} \mathrm{C}$. The initial permeability and pore volume of the testing sandpack were $1.47 \mu \mathrm{m}^{2}$ and $33.0 \mathrm{~mL}$ respectively. Figure 8 shows the permeability reduction of the combined gel as a function of 


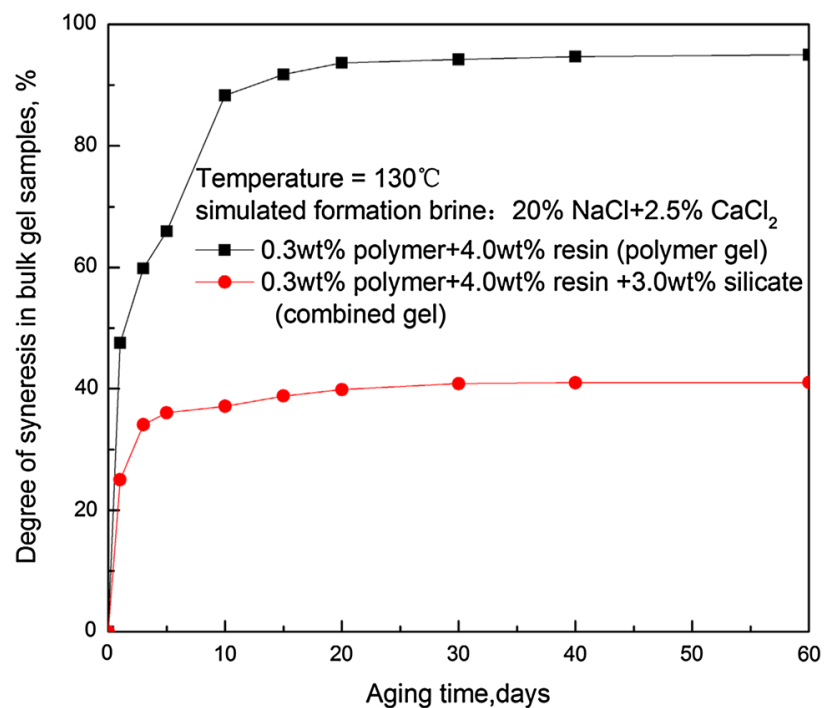

Fig. 7 The degree of syneresis observed in bulk gel samples of polymer gel and combined gel versus aging time

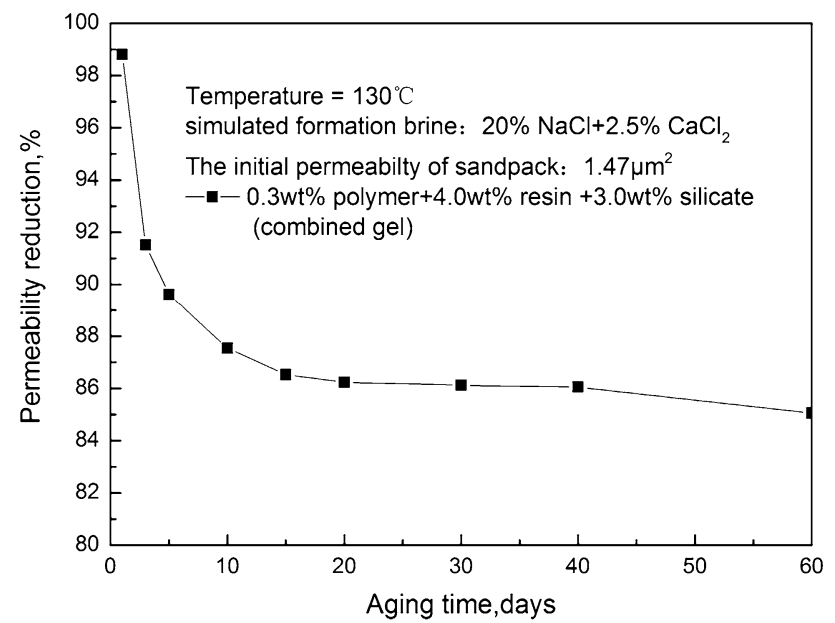

Fig. 8 The permeability reduction of combined gel versus aging time

aging time. For the organic/inorganic combined gel composed of $0.3 \mathrm{wt} \%$ polymer, $4.0 \mathrm{wt} \%$ resin and 3.0 $\mathrm{wt} \%$ inorganic silicate, after aging for 60 days at $130{ }^{\circ} \mathrm{C}$, the combined gel showed approximately $85 \%$ permeability reduction.

\section{Conclusions}

(1) According to proper gelation time and economical cost, the formulation of the organic/inorganic combined gel was optimized as follows: the polymer concentration was $0.2-0.3 \mathrm{wt} \%$, the phenol formaldehyde resin concentration was $2.5-4.0 \mathrm{wt} \%$ and the inorganic silicate concentration was $3.0-5.0 \mathrm{wt} \%$.
(2) The gelation time decreased from 54.0 to $15.5 \mathrm{~h}$ with increasing temperature from 100 to $130{ }^{\circ} \mathrm{C}$. After aging for 60 days in simulated formation brine with high total dissolved solids (TDS: $20 \% \mathrm{NaCl}+2.5 \% \mathrm{CaCl}_{2}$ ) at $130{ }^{\circ} \mathrm{C}$, for the polymer gel composed of $0.3 \mathrm{wt} \%$ polymer and 4.0 wt $\%$ resin, about $92 \%$ syneresis was observed, while for the organic/inorganic combined gel composed of $0.3 \mathrm{wt} \%$ polymer, $4.0 \mathrm{wt} \%$ resin and $3.0 \mathrm{wt} \%$ inorganic silicate, about $40 \%$ syneresis was observed. The results indicated that the organic/inorganic combined gel had better longterm thermal stability and salt tolerance.

(3) Sandpack flow experimental results showed that for the organic/inorganic combined gel composed of $0.3 \mathrm{wt} \%$ polymer, $4.0 \mathrm{wt} \%$ resin and $3.0 \mathrm{wt} \%$ inorganic silicate, after aging for 60 days at $130{ }^{\circ} \mathrm{C}$, the combined gel showed approximately $85 \%$ permeability reduction.

Acknowledgments This work was financially supported by National S\&T Major Project (Grant No. 2011ZX05024-004) on chemical flooding in Bohai heavy oil reservoir and the "Taishan Scholars" Construction Engineering (No.ts20070704).

Open Access This article is distributed under the terms of the Creative Commons Attribution License which permits any use, distribution, and reproduction in any medium, provided the original author(s) and the source are credited.

\section{References}

Albonico P, Bartosek M, Malandrino A, Bryant S, Lockhart T (1995) Studies on phenol-formaldehyde crosslinked polymer gels in bulk and in porous media. In: Paper SPE 28983, presented at international symposium on oilfield chemistry, San Antonio, Texas pp 14-17

Al-Muntasheri G, Nasr-El-Din H, Al-Noaimi K, Zitha P (2009) A study of polyacrylamide-based gels crosslinked with polyethyleneimine. SPE J 14(2):245-251

Banerjee R, Ghosh B, Khilar K, Boukadi F, Bemani A (2008) Field application of phenol formaldehyde gel in oil reservoir matrix for water shut-off purposes. Energy Sour Part A 30(19): 1779-1787

Bryant SL, Bartosek M, Lockhart TP (1997) Laboratory evaluation of phenol-formaldehyde/polymer gelants for high-temperature applications. J Petrol Sci Eng 17(3):197-209

Eoff L, Dalrymple E, Everett D, Vasquez J (2007) Worldwide field applications of a polymeric gel system for conformance applications. SPE Prod Oper 22(2):231-235

Kabir A (2001) Chemical water and gas shutoff technology-an overview. In: Paper SPE 72119, presented at SPE Asia Pacific improved oil recovery conference, Kuala Lumpur, Malaysia, pp 6-9

Liang B, Li BY (2001) High strength combined gel CY-98 for selective water plugging: structure and properties. Oilfield Chem 18(1):27-30 (In Chinese)

Liu Y, Bai B, Wang Y (2010) Applied technologies and prospects of conformance control treatments in China. Oil Gas Sci Technol Revue d'IFP Energies nouvelles 65(6):859-878

Mary H, Wouter B, Aly H, Jarl V, John W (1999) The first carbonate field application of a new organically crosslinked water shutoff 
polymer system. In: Paper SPE 50738, presented at the SPE international symposium on oilfield chemistry, Houston, pp 16-19

Moradi-Araghi A (2000) A review of thermally stable gels for fluid diversion in petroleum production. J Petrol Sci Eng 26(1):1-10

Moradi-Araghi A, Bjornson G, Doe P (1993) Thermally stable gels for near-wellbore permeability contrast corrections. SPE Adv Technol Ser 1(1):140-145

Nasr-El-Din H, Taylor K (2005) Evaluation of sodium silicate/urea gels used for water shut-off treatments. J Petrol Sci Eng 48(3): 141-160

Sengupta B, Sharma V, Udayabhanu G (2012) Gelation studies of an organically cross-linked polyacrylamide water shut-off gel system at different temperatures and $\mathrm{pH}$. J Petrol Sci Eng $81: 145-150$

Sydansk R (1988) A new conformance-improvement-treatment chromium gel technology. In: Paper SPE 17329, SPE presented at the SPE enhanced oil recovery symposium, Tulsa, Oklahoma pp 16-21

Sydansk R, Southwell G (2000) More than 12 years? Experience with a successful conformance-control polymer-gel technology. Old Prod Facil 15(4):270-278

Vasquez J, Dalrymple E, Eoff L, Reddy B, Civan F (2005) Development and evaluation of high-temperature conformance polymer systems. In: Paper SPE 93156, presented at SPE international symposium on oilfield chemistry, The Woodlands, Texas, pp 2-4

Yadav US, Mahto V (2013) Investigating the effect of several parameters on the gelation behavior of partially hydrolyzed polyacrylamide-hexamine-hydroquinone gels. Ind Eng Chem Res 52(28):9532-9537 